\title{
Management of Integrated Functional Adult Education Program: A Critical Analysis of Policy-Practice Gaps
}

\author{
Garkebo Basha Abo \\ Department of Adult Education and Community Development, College of Education and Behavioral Sciences, Haramaya \\ University, Haramaya, Ethiopia \\ Email: garadured2019@gmail.com
}

How to cite this paper: Abo, G. B. (2020). Management of Integrated Functional Adult Education Program: A Critical Analysis of Policy-Practice Gaps. Creative Education, 11, 1261-1288. https://doi.org/10.4236/ce.2020.118094

Received: June 10, 2020

Accepted: July 12, 2020

Published: August 13, 2020

Copyright $\odot 2020$ by author(s) and Scientific Research Publishing Inc. This work is licensed under the Creative Commons Attribution International License (CC BY 4.0).

http://creativecommons.org/licenses/by/4.0/ (c) (i) Open Access

\begin{abstract}
The purpose of this study was to critically analyze the policy-practice gaps in the Management of Integrated Functional Adult Education Program (IFAEP) in Hararghe Zones of Oromia regional state, Ethiopia. A survey research design with both qualitative and quantitative approaches involving concurrent triangulation strategy was used. A total of 215 respondents (facilitators, $\mathrm{n}=$ 195; coordinators, $\mathrm{n}=6$; experts, $\mathrm{n}=10$; and Education Bureau Heads (EBHs), $n=4$ ) were the samples. Except for facilitators (who were selected by stratified random sampling), all the rest participants were chosen by expert sampling. Questionnaires, interviews, FGDs, and Observations were tools of data collection. Descriptive and inferential statistics were used to analyze data. The findings of the study revealed that there are gaps between the current practice of IFAEP management and its policy implementation guidelines. The major gaps were observed in terms of planning, curricular orientation, implementation, stakeholders' participation, integration and, monitoring and evaluation. Lacks of professionals, educational inputs and budget as well as a dearth of incentives, commitment, visionary leadership, and IFAEP structure were generally the major challenges hampering IFAEP implementation. Cramer's $\mathrm{V}$ test result, except for sex, indicated a positive association between subject variables and IFAEP implementation. The correlation matrix also revealed a moderate relationship between IFAEP implementation and the predictor variables. Besides, the regression analysis showed that the major predictor variables in their order of significance (highest to least): planning, monitoring and evaluation, integration, curricular orientation, and participation affected the overall implementation of the IFAEP. Overall, it can be inferred that the current IFAEP is not managed as per the policy implementation guidelines implying that there exist policy-practice gaps in the manage-
\end{abstract}


ment of IFAEP in the study area. Thus, it is suggested that concerned bodies (Ministry of Education, Regional, Zonal, and District Education Bureaus) should give due attention to IFAEP/ANFE, make it to have its own structure and equip it with right human, material, and financial resources.

\section{Keywords}

Integrated Functional Adult Education, Management, Policy, Practice

\section{Introduction}

Functional adult education (FAE), which follows the functional conception of literacy (Papen, 2005), is conceptualized as the acquisition and use of 3Rs (reading, writing and numeracy) to learn practical knowledge and skills useful for other aspects of life, such as agriculture, health, civic and cultural education, primary health care, prevention of diseases (such as malaria, HIV/AIDS, TB, etc.), family planning, environmental protection, marketing, banking, gender equity, and so on. Functional adult education (which, here, is also referred to as integrated functional adult education (IFAE)) is considered as an approach to literacy education (Workineh, 2012). According to Sonja (2011), IFAE is conceived as the acquisition of the mechanical skills of the 3Rs, life skills, technical/vocational skills and business skills. Sandhaas (2009) asserted that IFAE builds on indigenous knowledge and seeks to link reading, writing and numeracy skills to livelihoods and skill training in areas such as agriculture, health, environmental protection, civic and cultural education, income generation, and so on.

According to MoE (2011), IFAE is not solely the acquisition of the 3Rs; rather it is an approach, process, and activity whereby adults begin discussing their individual or community needs, problems, and difficulties; read words, numbers, phrases and/or sentences reflecting these; and finally begin to write, read, and calculate around them. It is currently provided to adults in Ethiopia in an integrated fashion and hence the concept of Integrated Functional Adult Literacy (IFAE) is adopted. In IFAE, the approach is functional and directed towards satisfying the specific needs of adults.

The two-year IFAE program for 15 - 60 years old youths and adults provides mother tongue reading, writing, and arithmetic skills development integrated with practical knowledge and skills. It is work and production-oriented literacy designed to make use of inputs from other development workers (agriculture, health, income generation, saving, etc.) and builds on indigenous knowledge. It seeks to link numeracy and literacy skills to livelihoods and skills training in agriculture (including off-farm activities), health, civic and cultural education, etc. and requires delivery by various governmental and non-governmental service providers (MoE, 2015).

Adults, with their appreciable and long-standing life experiences, are the major productive segments of the society who are hopped to contribute much in 
realizing Ethiopia's national development policies, strategies and packages (agriculture and rural development, industrialization, health and packages related to youth and women) through active participation in adult education in general and in Integrated Functional Adult Education Program (IFAEP) in particular. According to the World Population Review (2020) report, adults constituted about half of the estimated 109 million of Ethiopia's population.

However, reports (such as UNESCO, 2019) show that about 36, 420,018 (33.4\%) of the adults in Ethiopia are functionally illiterate. From this, the lion share is taken up by Females (56.9\%) and the rest $43.1 \%$ are their counterparts. The situation in the present study area [East and West Haraghe Zones-abbreviated as EWHZ) is not quite different from this fact. To illustrate this, five years (2015/16-2019/20) adult statistics (Planned), Enrolled and Graduated were considered from these two Zones.

To begin with, the total population in the two zones were 5, 860,469, and from this, 3,291,335 (56\%) were estimated to be functionally illiterate (EWHZ Education Bureau, 2019). The target plan (P) to enroll (E) adults in IFAEP in the five years' time (2015/16-2019/20) was 2,774,986. From this, the actual enrollment (E) was 2,086,887. For the same period, the total number of adults who graduated in IFAEP was $1,066,100$. The computed percentage for $\mathrm{E}$ to $\mathrm{P} ; \mathrm{G}$ to $\mathrm{E}$ and $\mathrm{G}$ to $\mathrm{P}$ were $75 \%, 51.1 \%$ and $38.4 \%$ respectively. This shows that the total number of adults enrolled (E) in and graduated (G) from IFAEP compared to the plan (P) was low and, especially the total number of graduates $(\mathrm{G})$ compared to the plan (P) was too low (38.4\%) and lagging behind the targeted goal-100\% successful completion of the program.

In line with this, MoE (2017), in its ESDP IV (Education Sector Development Program IV) period, which is five years program, reported unsuccessful performance in IFAEP where the training of 1,938,000 (95\%) out of a total of 20.4 million functionally illiterate adults were planned. However, the actual achievement was the training of only 12 million adults (58.8\%).

At the national level, the targeted adult literacy rate at the end of ESDP V (by $2019 / 20$ ) is aspired to be $100 \%$ (MoE, 2015). However, as evidenced by the above figures, it seems that the target is short of its plan and lagging. This means that the expected number of adults did not get the opportunity of being trained in IFAEP and acquired knowledge, life skills and attitude that could have helped them earn their livelihoods in particular and contributed to the national economic growth and development in general.

MoE (2008), in its national adult education strategy (NAES) document, witnessing that the majority of the Ethiopian population are adults, it stressed an urgent need to reduce the number of functionally illiterate adults by $50 \%$ in 2015. This Ethiopia's commitment is in line with the Dakar's Framework for Action (2000). According to the Ethiopia National Human Development Report (2018), adult functional illiteracy is a factor holding back Ethiopia's human development within the Education Sub-Index. In ESDP-V it is stressed that a high level of functional illiteracy in the adult population is a barrier to achieving de- 
velopment goals, particularly that of achieving the lower-middle-income economy status by 2025. Effective management of IFAEP in terms of planning, relevance, participation, integration, implementation, monitoring and evaluation are the key determinants and backup the endeavor of pulling off the development goals of Ethiopia, especially its vision of becoming a lower-middle-income country by 2025 .

Attempts have been made by some authors to address issues related to the operation of adult education (AE) in the Eastern part of Ethiopia. For instance, Seyoum and Basha (2017) conducted a survey study on "Andragogical Methods to Sustain Quality Adult Education in Ethiopia-Eastern Ethiopia in focus." The study focused on addressing ways andragogy affects adult learning; the extent of implementation of active learning (ALMs) in adult classes; and testing level of experiencing of ALMs among adult learners. The major findings of the study revealed that ALMs were not adequately implemented; there was a mean difference between $1^{\text {st }}$ and $2^{\text {nd }}$-year adult learners in experiencing ALMs. The same authors conducted a survey study in 2019 on "Status and Relevance of Adult Education: Learners Perceived Experience in Eastern Ethiopia." The objectives of the study were to: examine the extent of relevance of $\mathrm{AE}$ to the lives of adult learners; assess the perception of adult learners about the AE; examine perception differences among adult learners with respect to some selected variables. The results of the study showed that the relevance of $\mathrm{AE}$ to the lives of adults was rated high and above; there was a perception difference among the adults (in favour of females) with respect to the relevance of AE; in addition, the results showed that female adult learners encountered challenges such as discrimination by facilitators, lack of confidence, more house chores, family care, etc.

A survey study entitled "Integrated Functional Adult Literacy: Existing Practices and Challenges in Eastern Ethiopia" was conducted by Awgichew and Seyoum (2017). The objectives of the study were to: assess the practice of the Integrated Functional Adult Education Program (IFALP) in the Eastern part of Ethiopia; examine extent of contribution of IFALP towards the improvement of the livelihood of the community; identify the major challenges in the implementation of IFALP. The findings of the study unfolded that adult education program contributed towards the reduction of harmful traditional practices; improved community participation in environmental conservation agenda; and enhanced societal life skills and usage of new agricultural technologies. Dysfunctional management structure, poor institutionalization, integration and coordination among the partner sectors as well as lack of resources (financial and human) were the major problems. One more survey study was conducted by Seyoum and Amdemeskel (2016) under the title, "Determinant of Adult Education Program: A Critical Analysis of Adult Education in Some Selected Training Centres of Eastern Regions". The focuses of the study were: to examine variables that are significantly associated with the success of adult learners in AE programs; identify challenges adult learners face in the AE program; and assess barriers accountable to affect learners' achievement in the AE program. The results 
of the study indicated the relationship of overall adult learning achievement to the assessment of learning; the methods of teaching used by facilitators were positive and significant; and the regression model showed overall adult learning condition was significantly affected by variables such as relevance of the content, methods of teaching, assessment of learning outcome, and locality of the adult education learners.

As can be noted from the aforementioned local studies, none of them focused on the Management of IFAEP: a critical analysis of policy-practice gaps in the East and West Hararghe Zones of Oromia Regional State. Of course, some researchers, such as Awgichew and Seyoum (2017) slightly touched some points related to the present study. However, the best part of the previous studies didn't stress on the specific issues in the present study area (which geographically, socio-culturally and socio-economically differ from the other parts of the Ethiopia and zones of the same region) the author of the present study is interested.

In addition, from my experience, as a practitioner (teacher educator, researcher, trainer of adult facilitators, workshop/conference organizer and participant, etc.) in the area of Adult education and community development, I had several opportunities to closely examine the way the current IFAE program (IFAEP) is generally managed. For instance, quite a lot of critical issues, formally and informally, have been raised by the stakeholders of adult education (such as facilitators, experts, coordinators, adult learners, consultative meeting participants, teacher educators, government bodies, partners and others) during various occasions such as trainings, national/international workshops, seminars, consultative meetings, during informal discussions, and curriculum development and review workshops. During these incidences, different pressing frustrations and complaints have been repetitively raised by the stakeholders. Some of the serious issues raised, but remained unaddressed, were related to the adult education (AE)/IFAEP policies, strategies, guidelines/manuals, the way AE/IFAEP is planned, organized, implemented, monitored and evaluated. As far as my reading is concerned, researches that fully address the important concerns raised by the AE/IFAEP stakeholders have not been researched in the present study area.

Thus, the policy-practice gaps and parameters that negatively affect the effective management of IFAEP have not been properly studied and documented holistically in the present study area. Hence, this study is meant to critically examine the policy-practice gaps in the management of IFAEP from the perspectives of the variables such as planning, relevance, implementation, participation, sectoral integration (shortened as "integration" in this paper), and monitoring and evaluation "vis-à-vis" the stipulated $\mathrm{AE}$ implementation policy guidelines, and come up with the practical recommendations so that the policymakers, experts, practitioners and other concerned bodies at different levels can make use of the findings derived from this study to improve the present status of the management of IFAEP in the present study areas and elsewhere.

Therefore, this study attempted to address the following basic research questions. viz. 
1) What is the practice of IFAEP management in terms of planning, relevance, implementation, participation, integration, and monitoring and evaluation in the study area?

2) What are the major challenges that impact the effective management of IFAEP in the study area?

3) What are the most important determinant variables of IFAEP implementation in the study area?

\section{Research Methods}

\subsection{Design}

A survey research design with both qualitative and quantitative approaches involving concurrent triangulation strategy was used to address the research problems. In this design (Creswell \& Plano, 2007), the investigator collects both forms of data at the same time during the study and then integrates the information in the interpretation of the overall results. In adopting concurrent procedures (Creswell, 2008), the researcher converges quantitative and qualitative data to provide a comprehensive analysis of the research problem. The basic assumption in employing this design (Creswell, 2012) is that combining both quantitative and qualitative methods provides a better understanding of the research problem and questions than either method by itself. Educators (such as Gay, Mills, \& Airasian, 2006) argue that all methods have their own strengths and weaknesses, and thus when used in combination, the rigor of one method overcomes the limitations of the other, i.e., biases inherent in any single method could neutralize or cancel the biases of other methods.

The variables picked to address the research problems were:

Dependent variable (DV)-Overall implementation of the IFAEP;

Independent variable (IV)-Sex, Age, Educational level, Educational Background, Year of service, Planning, Relevance, Participation, Integration, and Monitoring and Evaluation.

\subsection{Sources of Data}

Both primary and secondary sources of data were used. Primary data were collected from adult education experts, coordinators, facilitators, and Education Bureau Heads (EBHs), whereas secondary sources of data were gathered from documents like Integrated Functional Adult Literacy Curriculum Framework (MoE, 2011), Learning for Life: Master Plan for Adult Education” (MoE, 2010), NAES (MoE, 2008), Functional Adult Literacy Implementation Guideline (MoE, 2011) and MoE's annual education abstracts. In addition, Adult Education plans and reports were collected from zones and districts education bureaus.

\subsection{Population and Samples}

In the present study area, there were 35 rural districts, 677 kebeles (Kebele is the smallest administrative unit), 1,676 adult learning centers, 1,424 facilitators, 37 
coordinators (one from each district and Zone), 109 experts ( 3 from each district plus 2 from each zone) and $37 \mathrm{EBHs}$ (one from each district and zone). Since districts in the two zones were more or less homogeneous, $10 \%$ (Gebremedhin \& Tweeten, 1994) of them were taken, which are around 4 . Then, four of them were selected randomly. To take sample kebeles, the Standardized Sample Size Determination Table (SSSDT) developed by Bartlett, Kotrlik, and Higgins (2001) was employed. Accordingly, with this standardized Table with the conditions such as standard deviation $(p)=0.5$, margin of error $(d)=0.05$ and $t=1.65(t=$ corresponding alpha value) generates about a sample size of 196 for a population of about 677 (the closest lower number to 700 in the table). Once the sample size (about 196) was determined, actual kebeles to be included in the study were selected by using systematic random sampling.

As to the adult learning centers (ALCs), before they were sampled, only functional (active) adult learning centers (FALCs) were screened in close consultation with the ALCs' coordinators, experts and facilitators. Accordingly, from a total of 1,676 ALCs, about 1,100 ALCs were identified. Following the same procedures and conditions used to select kebeles above, from a total of 1,100 ALCs, 214 of them were selected as samples. Since facilitators working in these centers differ in terms of their academic levels (most being grade $10^{\text {th }}$ completes, some diploma and the rest $1^{\text {st }}$-degree holders), stratified random sampling was used. Accordingly, from a total of 1,424 facilitators, 195 of them were selected. Concerning the adult education coordinators, experts and, EBHs, expert sampling technique (Singh, 2007; Scott \& Morrison, 2006) was used as they are believed to have demonstrable experience and expertise in the present area of interest. Accordingly, from the two zones, a total of 6 coordinators, 10 experts, and $4 \mathrm{EBHs}$ were included. Thus, a total of 215 samples were the participants of the present study.

For the sake of ethical issues and as per the requests of the respondents, a consensus was reached between the researcher and research participants to keep their identity anonymous and use their responses (generated through FGDs and interviews) only for research purposes. Thus, their anonymity was maintained by using 3 letter codes to each interviewee and FGD participants. Accordingly, Exp 1, 2, 3, etc. for experts; Cor 1, 2, 3, etc. for coordinators; EBH 1, 2, 3, etc. for education bureau heads and $\mathrm{Fac} 1,2$, 3, etc. for facilitators were used to represent them.

\subsection{Methods of Data Collection}

Questionnaires, interview guides, Observation and FGDs were means of generating the required information. Questionnaires (composed of both close and open-ended items) were the major tool of data collection. The data collection process was assisted by trained enumerators, $\mathrm{AE}$ experts and coordinators. Interviews and FGDs were mainly facilitated by the researcher. Accordingly, opinions of the facilitators were surveyed through questionnaires which consisted of 47 summated ratings scale type items, whereas those of IFAE experts, coordi- 
nators and EBHs were explored through FGDs and semi-structured interviews. Ten comprehensive semi-structured questions were used for the interview and FGD - ten items for each group-interviewee and FGD group. A total of 15 individuals ( 3 coordinators, 5 experts, $2 \mathrm{EBHs}$ and 5 facilitators) participated in the interviews (\#7) and FGDs (\#8). Before conducting interviews and FGDs, convenient time and place were arranged in consultation with the interview and FGD participants. Accordingly, each interviewee was interrogated for about 30 40 minutes, whereas each FGD lasted for about 90 minutes. During the interview and FGDs, important points were jotted down and tape recorded. Amharic and Afaan Oromo (local languages) were used during the interviews and FGDs. Later on, information collected through these two vernacular languages were transcribed (recorded information) and translated into English language. Finally, an observation checklist was used to observe adult learning centres (location, center type, adult participation, their organization/status, etc.), schedules, and contents) and AE plans, reports (achievements and failure), and available guidelines/manuals. A total of 20 checklist items were developed and used for the observation purpose.

Before gathering the actual information, the reliability and validity of the items were checked. The Validity of the items was checked by the selected subject experts, IFAEP coordinators, facilitators and experts. As to the reliability of the items in the questionnaire, a pilot study was conducted. Facilitators $(n=20)$, who were not included in the major study, were chosen to fill out the questionnaires. Consequently, the average reliability coefficient for the items grouped under seven major variables (planning, implementation, relevance, participation, integration, and monitoring and evaluation) was found 0.83 , indicating that the items were internally consistent and hence, reliable. This reliability coefficient value is in line with the suggestion made by scholars such as Gay, Mills \& Airasian (2006) and Drost (2011). They suggested that items with a reliability coefficient of greater than or equal to 0.7 are reliable and hence, acceptable for the study.

\subsection{Data Analysis}

Once the required data were secured, both quantitative and qualitative methods of data analysis were used. Quantitative data were analyzed by employing descriptive and inferential (Cramer's $\mathrm{V}$ and t-tests, correlation matrix and multiple regression) statistics. SPSS, version 20 , was used to analyze the quantitative data. Qualitative data were analyzed through thematization and verbal narrations and merged with quantitative data.

\section{Results}

In this chapter, only the major findings (with few elaborations) are presented. The extended discussions of the same are made under Chapter 4.

\subsection{Subject Variables and Characteristics of the Respondents}

The major subject variables included in this study were sex, age, educational lev- 
el, educational background, and year of service. The brief account of the respondents is presented as follows.

As to the characteristics of the respondents, most of the facilitators (79\%), experts (100\%), and EBHs (100\%) were males. Concerning the age of the respondents, $44 / \%, 35.4 \%, 10.3 \%$ and $8.2 \%$ of the facilitators fell in the age ranges of $<20,20-29,30-39$ and $40-49$ respectively, whereas a great majority of the coordinators (60\%), experts (66.6\%), and EBHs (66.6\%) were categorized under 40 - 49, 40 - 49, and 50 - 59 respectively.

With regard to the educational level and background of the respondents, most of the facilitators $(55.4 \%)$ were $10^{\text {th }}$ grades complete. The rest were certificates (22.1\%), diploma (13.3\%) and $1^{\text {st }}$-degree holders $(9.2 \%)$. Nearly all of the coordinators, experts and EBHs were $2^{\text {nd }}$-degree holders. Interestingly, except for 8.2\% facilitators (graduated in adult education), all the rest, i.e., $90.8 \%$ facilitators, $100 \%$ of the experts, coordinators, and EBHs were non-adult graduates. They have few or no know-how about the IFAEP. Pertaining to the years of service, $40 \%, 23.1 \%, 15.9 \%, 12.3 \%$ and $8.7 \%$ of the facilitators, respectively, had 1 $5,6-10,11-15,16-20$ and above 21 years of experience, whereas the majority of the coordinators, experts, and EBHs had $11-21$ years of service.

Thus, from the foregoing presentation, it can be inferred that the majority of the respondents were males. Females are underrepresented though their no $(\mathrm{N}=$ $2,948,032)$ excels their counterparts $(\mathrm{N}=2,908,456)$ in the community. Most of the facilitators were young, less qualified and non-adult graduates with fewer years of service. The implication is that they are not up to the standard with the required andragogical skills to understand adult learners and facilitate their learning as per the guidelines. On the other hand, experts, coordinators, and EBHs were relatively better qualified (but non-adult graduates) with longer years of service than facilitators but with little or without knowledge about the art and science of AE. The ramification is that their contribution towards the effective implementation of adult education would be minimal.

In connection with this, attempts were also made to see the link between subject variables and IFAEP implementation. Accordingly, Cramer's V test was employed to examine the association and degree of association between subject variables (age, sex, educational level and background, and years of service) and the overall implementation of the IFAEP (Table 1).

Table 1. Cramer's V test of association between the subject variables and overall implementation of IFAEP.

\begin{tabular}{cc}
\hline Variable & Cramer's V \\
\hline Age & $0.16^{\mathrm{a}}$ \\
Sex & 0.07 \\
Educational level & $0.35^{\mathrm{a}}$ \\
Educational background & $0.41^{\mathrm{a}}$ \\
Year of Service & $0.38^{\mathrm{a}}$ \\
\hline
\end{tabular}

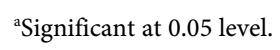


Accordingly, except for sex, all the variables showed positive associations with the overall implementation of the IFAEP. Moreover, Cramer's V was more than 0.25 which indicated the association between the subject variables and the overall implementation of IFAEP was very strong except for age which showed a kind of weak association.

\subsection{IFAEP Planning}

Respondents were requested to disclose their level of the agreement if the fundamental elements of planning are included in the IFAEP or not (Table 2).

Table 2. Views of the respondents about issues related to the planning of IFAEP.

\begin{tabular}{|c|c|c|c|c|c|c|c|c|c|c|c|}
\hline \multirow{3}{*}{$\mathrm{S} / \mathrm{N}$} & \multirow{3}{*}{$\begin{array}{l}\text { Items } \\
\text { There is a plan for: }\end{array}$} & \multicolumn{10}{|c|}{ Responses } \\
\hline & & \multicolumn{2}{|c|}{ Strongly agree (5) } & \multicolumn{2}{|c|}{ Agree (4) } & \multicolumn{2}{|c|}{ Undecided (3) } & \multicolumn{2}{|c|}{ Disagree (2) } & \multicolumn{2}{|c|}{ Strongly disagree (1) } \\
\hline & & $\mathrm{F}$ & $\%$ & $\mathrm{~F}$ & $\%$ & $\mathrm{~F}$ & $\%$ & $\mathrm{~F}$ & $\%$ & $\mathrm{~F}$ & $\%$ \\
\hline 1. & $\begin{array}{l}\text { Setting \& achieving of vision, mission, } \\
\text { goal \& values }\end{array}$ & 18 & 9.2 & 19 & 9.7 & 7 & 3.6 & 98 & 50.3 & 53 & 27.2 \\
\hline 3. & Staffing & 66 & 33.8 & 82 & 42.1 & 29 & 14.9 & $-{ }^{a}$ & $-^{\mathrm{a}}$ & 18 & 9.2 \\
\hline 4. & Staff capacity building & 54 & 27.7 & 100 & 51.3 & 1 & 0.5 & 19 & 9.7 & 21 & 10.8 \\
\hline 5. & Designing incentive packages & 21 & 10.8 & 17 & 8.7 & 1 & 0.5 & 79 & 40.5 & 74 & 30.88 \\
\hline 6. & Resource mobilization & 11 & 5.6 & 21 & 10.8 & 1 & 0.5 & 109 & 55.9 & 53 & 27.2 \\
\hline 8. & Budget & 66 & 33.8 & 78 & 40 & 3 & 1.5 & 20 & 10.3 & 28 & 14.4 \\
\hline 9. & Involving stakeholders & 9 & 4.6 & 26 & 13.3 & 3 & 1.5 & 119 & 61.0 & 38 & 19.5 \\
\hline 10. & Enrollment of adult learners & 64 & 32.8 & 98 & 50.3 & 4 & 2.1 & 20 & 10.3 & 9 & 4.6 \\
\hline 11. & Post literacy & 9 & 4.6 & 42 & 21.5 & 2 & 1.0 & 55 & 28.2 & 87 & 44.6 \\
\hline 12. & Averting functional illiteracy relapsing & 7 & 3.6 & 9 & 4.6 & 2 & 1.0 & 102 & 52.3 & 75 & 38.5 \\
\hline 13. & Monitoring and Evaluation & 2 & 1.0 & 13 & 6.7 & 2 & 1.0 & 135 & 69.2 & 43 & 22.1 \\
\hline
\end{tabular}

Note: ${ }^{\mathrm{a}}$ means no response.

As can be noted from Table 2, except for staffing (75.9\%), staff capacity building (79\%), enrollment of adult learners (83\%), budgeting (73.8\%), and efficient utilization of resources (75.9\%), all the rest planning activities of IFAEP, i.e., setting \& achieving of vision, mission, goal \& values $(77.5 \%)$, curricular need assessment $(81.6 \%)$, designing incentive packages $(71.38 \%)$, resource mobilization $(83.1 \%)$, involving stakeholders $(80.5 \%)$, post-literacy $(72.8 \%)$, averting functional illiteracy relapsing (91.8\%), and monitoring and evaluation $(91.3 \%)$ were not planned as indicated by the majority of the respondents.

\subsection{Implementation of IF AEP}

In this section, respondents were inquired to make their judgment about the extent of implementation of IFAEP (Table 3). 
Table 3. Views of the respondents about the extent of Implementation of IFAEP.

\begin{tabular}{|c|c|c|c|c|c|c|c|c|c|c|c|}
\hline \multirow{3}{*}{$\mathrm{S} / \mathrm{N}$} & \multirow{3}{*}{$\begin{array}{c}\text { Items } \\
\text { Extent of: }\end{array}$} & \multicolumn{10}{|c|}{ Responses } \\
\hline & & \multicolumn{2}{|c|}{ Very high (5) } & \multicolumn{2}{|c|}{ High (4) } & \multicolumn{2}{|c|}{ Moderate (3) } & \multicolumn{2}{|c|}{ Low (2) } & \multicolumn{2}{|c|}{ Very low (1) } \\
\hline & & $\mathrm{F}$ & $\%$ & $\mathrm{~F}$ & $\%$ & $\mathrm{~F}$ & $\%$ & $\mathrm{~F}$ & $\%$ & $\mathrm{~F}$ & $\%$ \\
\hline & Facilitation skills of the facilitators & 4 & 2.1 & 11 & 5.6 & 26 & 13.3 & 86 & 44 & 68 & 34.9 \\
\hline 2. & Assessment of learners & $-{ }^{\mathrm{a}}$ & $-{ }^{\mathrm{a}}$ & 1 & .5 & 6 & 3.1 & 95 & 48.7 & 93 & 47.7 \\
\hline 3. & Special treatment of adults with disabilities & $-{ }^{\mathrm{a}}$ & $-{ }^{\mathrm{a}}$ & 8 & 4.1 & $-a^{a}$ & $-{ }^{\mathrm{a}}$ & 40 & 20.5 & 147 & 75.4 \\
\hline 4. & Separation of adult classes by levels (level I \&II) & $-{ }^{\mathrm{a}}$ & $-{ }^{\mathrm{a}}$ & 75 & 38.5 & 5 & 2.6 & $-{ }^{\mathrm{a}}$ & $-{ }^{\mathrm{a}}$ & 115 & 59.0 \\
\hline 5. & Separation of youths and Adults during lesson delivery in class & $-{ }^{\mathrm{a}}$ & $-{ }^{\mathrm{a}}$ & 3 & 1.5 & 3 & 1.5 & 8 & 4.1 & 181 & 92.8 \\
\hline 6. & Utilization of audio-visual media to support adult learning & 6 & 3.1 & 24 & 12.3 & 31 & 15.9 & 74 & 37.9 & 60 & 30.8 \\
\hline 7. & Supporting theoretical classes with practical works & 5 & 2.6 & 2 & 1.0 & 4 & 2.1 & 23 & 11.8 & 161 & 82.6 \\
\hline 8 & Implementing IFAEP [MoE’s] guidelines, in general & 3 & 1.5 & 7 & 3.6 & 9 & 4.6 & 54 & 27.7 & 123 & 62.6 \\
\hline
\end{tabular}

Note: Overall implementation value was obtained/computed by "transforming" all the items into a single item (named Overall implementation) by using SPSS (v.20). - ${ }^{\mathrm{a}}$ means no response.

As can be understood from Table 3 above, facilitators (volunteers, employed, formal school teachers, development agents, etc.) lacked facilitation skills (77\%) implying that the program is run by unprofessionals; adults with disabilities/special needs were not sorted out and special treatments were not made (96.4\%); youths and adults (who of course differed in their ages and life experiences) were congested in the same class and made them learn the same content, in the same time and pace (92.8\%); theoretical classroom lessons were not supplemented by teaching aids (audio-visual materials) (68.7\%); and practical lessons (such as workshops, CSLCs, field visits to model sites; experience sharing, etc) were not organized (82.6\%).

Besides, attempts were made to see if two Zones (EWHZs) significantly differ in terms of the implementation of IFAEP (Table 4).

Table 4. Comparison of IFAEP implementation between EWHZs

\begin{tabular}{ccccc}
\hline & Mean $(\mathrm{M})$ & $\mathrm{SD}$ & $\mathrm{t}$ & $\mathrm{P}$ \\
\hline East Hararghe & 2.027 & 1.12674 & & \\
West Hararghe & 1.196 & 0.40098 & 5.861 & 0.001 \\
\hline
\end{tabular}

East Hararghe $(\mathrm{M}=2.027 ; \mathrm{SD}=1.12)$ and West Hararghe $(\mathrm{M}=1.19 ; \mathrm{SD}=$ $0.40)$ Zones with $t=5.86, p<0.01$ differed statistically in terms of the implementation of IFAEP. Though the level of implementation is low in both zones, their mean scores imply that the overall implementation of IFAEP is relatively better in East Hararghe zone (EHZ). This relatively better performance observed in IFAEP in EHZ is mainly attributed to relatively better staffing (in terms of number and training), commitment and organization. However, the overall low performances noticed in the two Zones call for a rethinking of the way IFAEP is 
managed in the two Zones.

\subsection{Relevance (Curricular Orientation) of the IFAEP}

Respondents were asked to rate the extent of relevance of the IFAEP to the adult learners (Table 5).

Table 5. Views of the respondents about the relevance of the IFAEP.

\begin{tabular}{|c|c|c|c|c|c|c|c|c|c|c|c|}
\hline \multirow{3}{*}{$\mathrm{S} / \mathrm{N}$} & \multirow{3}{*}{$\begin{array}{c}\text { Items } \\
\text { Relevance in: }\end{array}$} & \multicolumn{10}{|c|}{ Responses } \\
\hline & & \multicolumn{2}{|c|}{ Very high (5) } & \multicolumn{2}{|c|}{ High (4) } & \multicolumn{2}{|c|}{ Moderate (3) } & \multicolumn{2}{|c|}{ Low (2) } & \multicolumn{2}{|c|}{ Very low (1) } \\
\hline & & $\mathrm{F}$ & $\%$ & $\mathrm{~F}$ & $\%$ & $\mathrm{~F}$ & $\%$ & $\mathrm{~F}$ & $\%$ & $\mathrm{~F}$ & $\%$ \\
\hline 1. & Improving agricultural practices & 59 & 30.3 & 65 & 33.3 & 55 & 28.2 & 8 & 4.1 & 8 & 4.1 \\
\hline 2. & $\begin{array}{l}\text { Creating/improving income generation \& de- } \\
\text { velop a culture of saving }\end{array}$ & 56 & 28.7 & 66 & 33.8 & 55 & 14.2 & 14 & 7.2 & 4 & 2.1 \\
\hline 3. & $\begin{array}{l}\text { Leading a healthy life (hygiene, nutrition, family } \\
\text { planning, etc) }\end{array}$ & 76 & 39.0 & 56 & 28.7 & 48 & 24.6 & 13 & 6.7 & 2 & 1.0 \\
\hline 4. & Understanding gender equality & 55 & 28.2 & 69 & 35.4 & 42 & 21.5 & 25 & 12.8 & 4 & 2.1 \\
\hline 5. & Learning civic and ethical education & 77 & 39.5 & 58 & 29.7 & 36 & 18.5 & 16 & 8.2 & 8 & 4.1 \\
\hline 6. & $\begin{array}{l}\text { Developing a culture of collaborative work, } \\
\text { cooperative learning, etc }\end{array}$ & 74 & 37.9 & 60 & 30.8 & 40 & 20.5 & 20 & 10.3 & 1 & 0.5 \\
\hline
\end{tabular}

The significance of the IFAEP to adult learners (items 1 - 6) in terms of improving their agricultural practices (plant and animal farming, conservation) and culture of cooperative learning and collaborative work, leading a healthy life (hygiene, nutrition, family planning, etc.), Creating/improving income generation \& developing a culture of saving, perceiving gender equality, and understanding of civic and ethical education were appreciably rated by the majority of the respondents as moderate and above, albeit few respondents revealed some degree of repudiations. In connection with these, informants were interviewed for further exploration of the issues raised.

\subsection{Integration in the Implementation of IFAEP}

In this section, respondents were solicited to make their judgment about the extent of integration in IFAEP implementation (Table 6).

Table 6. Views of the respondents about the extent of integration in IFAEP implementation.

\begin{tabular}{|c|c|c|c|c|c|c|c|c|c|c|c|c|c|}
\hline \multirow{3}{*}{$\mathrm{S} / \mathrm{N}$} & \multirow{3}{*}{ Item } & \multicolumn{12}{|c|}{ Responses } \\
\hline & & \multicolumn{2}{|c|}{$\begin{array}{c}\text { Very High } \\
(6)\end{array}$} & \multicolumn{2}{|c|}{$\begin{array}{l}\text { High } \\
(5)\end{array}$} & \multicolumn{2}{|c|}{$\begin{array}{c}\text { Moderate } \\
\text { (4) }\end{array}$} & \multicolumn{2}{|c|}{$\begin{array}{l}\text { Low } \\
(3)\end{array}$} & \multicolumn{2}{|c|}{$\begin{array}{l}\text { Very Low } \\
\text { (2) }\end{array}$} & \multicolumn{2}{|c|}{$\begin{array}{c}\text { No integration } \\
\text { (1) }\end{array}$} \\
\hline & & $\mathrm{F}$ & $\%$ & $\mathrm{~F}$ & $\%$ & $\mathrm{~F}$ & $\%$ & $\mathrm{~F}$ & $\%$ & $\mathrm{~F}$ & $\%$ & $\mathrm{~F}$ & $\%$ \\
\hline 1. & $\begin{array}{c}\text { Integration among } \\
\text { partner sectors } \\
\text { (Integration) }\end{array}$ & 5 & 2.6 & 2 & 1.0 & 6 & 3.1 & 30 & 15.4 & 46 & 23.6 & 106 & 54.4 \\
\hline
\end{tabular}


A great proportion of the respondents claimed their views that the degree of integration was non-existent (54.4\%), followed by very low $(23.6 \%)$ and low (15.4\%). These findings are in congruence with reflections made during the interviews and FGDs.

\subsection{Participation of Stakeholders in the Implementation of the IFAEP}

In this section, respondents were requested to rate the extent of involvement of stakeholders in the implementation of the IFAEP (Table 7).

Table 7. Views of the respondents about the participation of stakeholders in the implementation of the IFAEP.

\begin{tabular}{|c|c|c|c|c|c|c|c|c|c|c|c|c|c|}
\hline \multirow{3}{*}{$\mathrm{S} / \mathrm{N}$} & \multirow{3}{*}{$\begin{array}{c}\text { Items } \\
\text { Participation of: }\end{array}$} & \multicolumn{12}{|c|}{ Responses } \\
\hline & & \multicolumn{2}{|c|}{$\begin{array}{l}\text { Very high } \\
\text { (6) }\end{array}$} & \multicolumn{2}{|c|}{$\begin{array}{l}\text { High } \\
(5)\end{array}$} & \multicolumn{2}{|c|}{$\begin{array}{l}\text { Moderate } \\
\text { (4) }\end{array}$} & \multicolumn{2}{|c|}{$\begin{array}{l}\text { Low } \\
(3)\end{array}$} & \multicolumn{2}{|c|}{$\begin{array}{l}\text { Very low } \\
\text { (2) }\end{array}$} & \multicolumn{2}{|c|}{$\begin{array}{c}\text { Not at all } \\
\text { (1) }\end{array}$} \\
\hline & & $\mathrm{F}$ & $\%$ & $\mathrm{~F}$ & $\%$ & $\mathrm{~F}$ & $\%$ & $\mathrm{~F}$ & $\%$ & $\mathrm{~F}$ & $\%$ & $\mathrm{~F}$ & $\%$ \\
\hline 1. & $\begin{array}{l}\text { NG and Civic } \\
\text { Organizations }\end{array}$ & $-{ }^{\mathrm{a}}$ & $-{ }^{\mathrm{a}}$ & 7 & 3.6 & 13 & 6.7 & 16 & 8.2 & 99 & 50.8 & 60 & 30.8 \\
\hline 2. & Facilitators & 13 & 6.7 & 9 & 4.6 & 9 & 4.6 & 84 & 43.1 & 69 & 35.4 & 11 & 5.6 \\
\hline 3. & Learners & 13 & 6.7 & 55 & 28.2 & 96 & 49.2 & 18 & 9.2 & 13 & 6.7 & $-^{\mathrm{a}}$ & $-^{a}$ \\
\hline 4. & Local community & 10 & 5.1 & 14 & 7.2 & 59 & 30.3 & 71 & 36.4 & 39 & 20.0 & 2 & 1.0 \\
\hline
\end{tabular}

NG-Non-governmental; - - - No response.

A great number of the respondents rated the engagement of the NG and Civic organizations very low (50.8\%) and non-existent (30.8\%). Similarly, the participation of the facilitators in a creating conducive learning-teaching environment for adult learners was rated by the majority as low (43.1\%) and very low (35.4\%), and that of the local community as low (36.4\%), moderate (30.3\%) and very low (20\%). On the contrary, the involvement of the adult learners in the implementation of the IFAEP was moderate (49.2\%) and high (28.2\%).

\subsection{Monitoring and Evaluation of IFAEP}

Respondents were asked to reveal their level of agreement about the practice of monitoring and evaluation (M\&E). Accordingly, their level of agreement about the practice of M\&E in the implementation of IFAEP is shown in Table 8.

Table 8. Views of the respondents about the monitoring and evaluation of IFAEP.

\begin{tabular}{|c|c|c|c|c|c|c|c|c|c|c|c|}
\hline \multirow{3}{*}{\multicolumn{2}{|c|}{ Items }} & \multicolumn{10}{|c|}{ Responses } \\
\hline & & \multicolumn{2}{|c|}{$\begin{array}{l}\text { Strongly } \\
\text { agree (5) }\end{array}$} & \multicolumn{2}{|c|}{ Agree (4) } & \multicolumn{2}{|c|}{ Undecided (3) } & \multicolumn{2}{|c|}{ Disagree (2) } & \multicolumn{2}{|c|}{$\begin{array}{c}\text { Strongly } \\
\text { disagree (1) }\end{array}$} \\
\hline & & $\mathrm{F}$ & $\%$ & $\mathrm{~F}$ & $\%$ & $\mathrm{~F}$ & $\%$ & $\mathrm{~F}$ & $\%$ & $\mathrm{~F}$ & $\%$ \\
\hline & There is learner enrollment, follow-up and recording & 50 & 25.6 & 75 & 38.5 & 7 & 3.6 & 35 & 17.9 & 28 & 14.4 \\
\hline 2. & There is a record of progression and regression of learners & 26 & 13.3 & 24 & 12.3 & $-^{\mathrm{a}}$ & 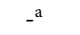 & 89 & 45.6 & 56 & 28.7 \\
\hline
\end{tabular}




\section{Continued}

\begin{tabular}{|c|c|c|c|c|c|c|c|c|c|c|c|}
\hline 3. & There is a system of handling complaints and feedbacks & 19 & 9.7 & 21 & 10.8 & 3 & 1.5 & 55 & 28.2 & 97 & 49.7 \\
\hline 4. & Achievement of IFAEP is assessed through standard tools & 11 & 5.6 & 7 & 3.6 & 2 & 1.0 & 128 & 65.6 & 47 & 24.1 \\
\hline 5. & $\begin{array}{l}\text { Performance of IFAEP is appraised via discussion with } \\
\text { concerned bodies (stakeholders \& partners) periodically }\end{array}$ & 9 & 4.6 & 8 & 4.1 & 7 & 3.6 & 156 & 80.0 & 15 & 7.7 \\
\hline 6. & $\begin{array}{l}\text { The Overall operation of IFAEP is assessed through formal } \\
\text { reporting }\end{array}$ & 72 & 36.9 & 82 & 42.1 & 9 & 4.6 & 13 & 6.7 & 19 & 9.7 \\
\hline
\end{tabular}

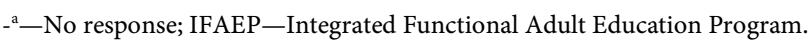

As can be noted from the results, diverse views were reflected about item no 1 (learner enrollment, follow-up and recording). Accordingly, the majority of the respondents $(64.1 \%)$ revealed their consent, whereas about $32.3 \%$ of them held a different view. Concerning the rest items, except for item no 6 (Assessment of the overall operation of IFAEP through formal reporting $-79 \%$ ), which was assessed positively; the respondents chiefly expressed their disapproval.

\subsection{Challenges That Impede the Implementation of IFAEP}

In this section, respondents were requested to reveal their level of agreement about the major challenges that potentially affect IFAEP implementation as presented in Table 9.

Table 9. Views of the respondents about the challenges of IFAEP implementation.

\begin{tabular}{|c|c|c|c|c|c|c|c|c|c|c|c|}
\hline \multirow{3}{*}{$\mathrm{S} / \mathrm{N}$} & \multirow{3}{*}{ Items } & \multicolumn{10}{|c|}{ Responses } \\
\hline & & \multicolumn{2}{|c|}{ Strongly agree (5) } & \multicolumn{2}{|c|}{ Agree (4) } & \multicolumn{2}{|c|}{ Undecided (3) } & \multicolumn{2}{|c|}{ Disagree (2) } & \multicolumn{2}{|c|}{ Strongly disagree (1) } \\
\hline & & $\mathrm{F}$ & $\%$ & $\mathrm{~F}$ & $\%$ & $\mathrm{~F}$ & $\%$ & $\mathrm{~F}$ & $\%$ & $\mathrm{~F}$ & $\%$ \\
\hline 1. & $\begin{array}{l}\text { Lack of clear vision, mission, values and } \\
\text { goals related to IFAEP }\end{array}$ & 68 & 34.9 & 89 & 45.6 & 18 & 9.2 & 14 & 7.2 & 6 & 3.1 \\
\hline 2. & Lack of clear understanding about IFAEP & 59 & 30.3 & 94 & 48.2 & 6 & 3.1 & 20 & 10.3 & 16 & 8.2 \\
\hline 3. & Lack of trained IFAEP staff & 81 & 41.5 & 78 & 40.0 & 7 & 3.6 & 14 & 7.2 & 15 & 7.7 \\
\hline 4. & Lack of budget & 98 & 50.3 & 85 & 43.6 & 3 & 1.5 & 7 & 3.6 & 2 & 1.0 \\
\hline 5. & Lack of required resources & 71 & 36.4 & 76 & 39.0 & 4 & 2.1 & 20 & 10.3 & 24 & 12.3 \\
\hline 6. & $\begin{array}{l}\text { Lack of interest, motivation } \\
\text { and commitment by IFAEP staff }\end{array}$ & 75 & 38.5 & 78 & 40.0 & 9 & 4.6 & 17 & 8.7 & 16 & 8.2 \\
\hline 7. & $\begin{array}{l}\text { Lack of interest, motivation and } \\
\text { commitment by IFAEP learners }\end{array}$ & 11 & 5.6 & 19 & 9.7 & 3 & 1.5 & 101 & 51.8 & 61 & 31.3 \\
\hline 8. & Lack of adequate payments to IFAEP staff & 91 & 46.7 & 87 & 44.6 & 2 & 1.0 & 8 & 4.1 & 7 & 3.6 \\
\hline 9. & Lack of IFAEP guidelines & 67 & 34.4 & 93 & 47.7 & 7 & 3.6 & 19 & 9.7 & 9 & 4.6 \\
\hline 10. & Lack of sectoral integration & 82 & 42.1 & 89 & 45.6 & 3 & 1.5 & 11 & 5.6 & 10 & 5.1 \\
\hline
\end{tabular}

Interestingly, except for item no 7 (lack of interest, motivation and commitment by IFAEP learners), which was indicated by the majority of the respondents $(83.1 \%)$ as a non-affecting factor, all the rest factors such as lack of clear 
vision, mission, values and goals (84.8\%), a clear understanding about IFAEP (78.5\%), trained IFAEP staff (81.5\%), budget (93.9\%), required resources (75.4\%), interest, motivation \& commitment by IFAEP staff (78.5\%), adequate payments for IFAEP staff (91.3\%), IFAEP guidelines $(82.1 \%)$ and integration $(87.7 \%)$ were reported to be the major factors negatively affecting the effective implementation of the IFAEP in the study areas.

Correlation Matrix

Correlation matrix (Pearson's Correlation) was also computed to examine the relationship between quantitative variables and IFAEP implementation. The results of the correlations are summarized in Table 10.

Table 10. Correlation Matrix for the overall implementation of IFAEP and predictor variables.

\begin{tabular}{|c|c|c|c|c|c|c|c|}
\hline $\mathrm{S} / \mathrm{N}$ & Variables & 1 & 2 & 3 & 4 & 5 & 6 \\
\hline 1. & Planning & 1 & & & & & \\
\hline 2. & Relevance & $-0.214^{\mathrm{b}}$ & 1 & & & & \\
\hline 3. & Participation & -0.033 & $0.214^{\mathrm{b}}$ & 1 & & & \\
\hline 4. & Sectoral integration & -0.151 & -0.101 & $0.339^{\mathrm{bb}}$ & 1 & & \\
\hline 5. & Monitoring \& evaluation & $-0.360^{\mathrm{bb}}$ & -0.099 & $-0.288^{\mathrm{bb}}$ & $-0.257^{\mathrm{bb}}$ & 1 & \\
\hline 6. & Overall implementation & $0.259^{\mathrm{bb}}$ & $-0.164^{\mathrm{b}}$ & $0.378^{\mathrm{bb}}$ & $0.362^{\mathrm{bb}}$ & $0.484^{\mathrm{bb}}$ & 1 \\
\hline
\end{tabular}

${ }^{\mathrm{b}}$ Correlation is significant at 0.05 level (2-tailed). ${ }^{\mathrm{bb}}$ Correlation is significant at the 0.01 level (2-tailed).

As can be noted from Table 10, significant relationships between overall implementation and the predictor variables were identified. Accordingly, the Pearson correlation results for planning and overall implementation $(\mathrm{r}=0.259, p<$ $0.01)$ implied that there is a positive and significant but moderate relationship. Relevance and overall implementation $(r=-0.164, p<0.05)$ indicated that both variables were inversely related and imply that there is a high perception of relevance about IFAEP but the implementation remained low in the study areas. The relationship between overall implementation of IFAEP and other components such as participation $(r=0.378)$, integration $(r=0.362)$, monitoring and evaluation $(r=0.484)$ were significant $(p<0.05)$ and moderate and implied that improving their status will increase overall implementation.

\subsection{Determinants of IFAEP Implementation}

To identify the significant predictor variable(s) from among the major independent variables (planning, relevance, participation, sectoral integration, and monitoring and evaluation), regression analysis was run (Table 12).

Before running the regression analysis, the normality of the data was checked. Accordingly, Kolmogorov-Smirnov and Shapiro-Wilks' tests were employed to confirm the normality of the data collected from the sample populations as presented in Table 11. 
Table 11. Test of normality for regression residuals of the overall implementation.

\begin{tabular}{cccccc}
\hline & \multicolumn{3}{c}{ Kolmogorov-Smirnov } & \multicolumn{3}{c}{ Shapiro-Wilk } \\
\hline Statistic & $\mathrm{df}$ & Sig. & Statistic & df & Sig. \\
\hline 0.146 & 122 & 0.200 & 0.945 & 122 & 0.356 \\
\hline
\end{tabular}

The significance of the two tests (Kolmogorov-Smirnov\& Shapiro-Wilk) for the normal distribution in the null hypothesis vs. non-normal under alternative hypothesis suggested the assumption of the linear regression model was not violated, confirming that data were generated from the normally distributed sample population. Following this, regression analysis was conducted to see whether or not the predictor variables, planning, relevance, participation, sectoral integration, monitoring and evaluation) had a significant impact on the overall implementation of the IFAEP.

Thus, looking at the factors (predictor variables) that affect the overall implementation of IFAEP was vital, and thus they were included in the regression model. Before model fitting, the multicollinearity problem was checked using VIF and Tolerance. From Table 12, VIF results for all variables were less than 5 which indicates there is no problem of multicollinearity in the model.

Table 12. Regression analysis of the overall Implementation of IFAEP against predictor variables.

\begin{tabular}{|c|c|c|c|c|c|c|c|c|c|}
\hline \multirow{2}{*}{ Model } & \multicolumn{2}{|c|}{$\begin{array}{l}\text { Unstandardized } \\
\text { Coefficients }\end{array}$} & \multirow{2}{*}{$\begin{array}{c}\text { Standardized } \\
\text { Coefficients } \\
\text { Beta }\end{array}$} & \multirow[t]{2}{*}{$\mathrm{t}$} & \multirow{2}{*}{ Sig. } & \multicolumn{2}{|c|}{$\begin{array}{l}95.0 \% \text { Confidence } \\
\text { Interval for B }\end{array}$} & \multicolumn{2}{|c|}{ Collinearity Statistics } \\
\hline & B & Std. Error & & & & Lower Bound & Upper Bound & Tolerance & VIF \\
\hline (Constant) & 5.055 & 0.731 & $-^{\mathrm{a}}$ & 6.919 & 0.000 & 3.608 & 6.501 & $-{ }^{\mathrm{a}}$ & $-{ }^{\mathrm{a}}$ \\
\hline Planning & 1.025 & 0.341 & 0.259 & 3.003 & 0.003 & 0.349 & 1.700 & 1.000 & 1.000 \\
\hline Relevance & -0.173 & 0.067 & -0.184 & -2.594 & 0.011 & -0.304 & -0.041 & 0.900 & 1.111 \\
\hline Participation & 0.177 & 0.091 & 0.149 & 1.940 & 0.05 & -0.004 & 0.358 & 0.762 & 1.313 \\
\hline Sectoral integration & 0.189 & 0.084 & 0.170 & 2.246 & 0.027 & 0.022 & 0.355 & 0.787 & 1.271 \\
\hline Monitoring and Evaluation & 0.273 & 0.120 & 0.160 & 2.278 & 0.025 & 0.510 & 0.036 & 0.911 & 1.098 \\
\hline
\end{tabular}

Significant at $0.05 ;{ }^{\mathrm{a}}-\mathrm{N}$ - response. Dependent Variable: Overall implementation of the IFAEP.

The predictor variable planning was a significantly affecting variable in the model $(\mathrm{B}=1.025, p<0.01)$ which indicated that increasing the planning scheme of IFAEP activities by a unit also increases the overall implementation by a proportion of 1.025. Furthermore, it can be seen from the regression coefficients that this predictor is the most influential and the implication is that working more on planning each activity in the program facilitates the implementation of IFAEP.

Monitoring and evaluation $(\mathrm{B}=0.487, p<0.05)$ was another predictor variable in the model that strongly affects the overall implementation IFAEP just next to planning. The result suggests that for a unit improvement in the monitoring and evaluation system, the overall implementation of IFAEP will be improved by 
a proportion of 0.487 .

A statistically significant but negative relationship was found with relevance $(\mathrm{B}=-0.173, p<0.05)$, indicated that though the respondents have a high level of perception about its relevance, the level of the overall implementation of IFAEP is low.

Participation of the stakeholders $(B=0.177, p \leq 0.05)$ was another predictor variable that is significantly and positively (but weak) affected the overall implementation. The interpretation is that for a unit change in the improvement of the participation of the stakeholders, there will be an increase by a proportion of 0.177 in the overall implementation of the IFAEP.

Lastly, the overall implementation was found significantly and positively related to integration ( $\mathrm{B}=0.189, p<0.05)$, indicating that as the status of integration is improved, overall implementation will be increased by 0.189 proportionally.

\section{Discussions}

In this paper, attempts have been made to examine the policy-practice gaps in the management of IFAEP in East and West Hararghe Zones of Oromia region. To this end, three research questions related to 1) the Practice of IFAEP management in terms of planning, relevance, participation, implementation, integration, and monitoring and evaluation; 2) Major challenges that impact the effective management of IFAEP and; 3) The most important/determinant variables of IFAEP implementation in the study area. Finally, lessons drawn and implications to IFAEP have been deliberated.

To begin with planning, it is conceived as the process of setting goals, developing strategies, outlining the implementation arrangements and allocation of resources to achieve the intended goals (UNDP, 2009). According to Kowalski (1998), it entails vital aspects of leadership (knowing what should be done) and management (knowing how to do it). Kotter (1991), in Nafukho, et al. (2011) noted that for [AE] managers to be successful in their work, they must pay attention to planning and budgeting, organizing and staffing, and controlling and problem-solving. Thus, from the above concise explanations, it seems clear that planning is a cornerstone of the goal we wish to attain-here, effective management of IFAEP.

Having the above prefatory remarks in mind, as shown in Table 2, respondents were solicited to reveal their level of the agreement if the basic elements (\#13) of the planning (collected from literatures and guidelines) were included in the IFAEP planning or not. Accordingly, from a total of 13 items, only five of them (staffing, capacity building, enrollment of adult learners, budgeting, and efficient utilization of resources) were planned while leaving behind most of the crucial activities (such as setting, sharing and achieving of vision, mission, goal and values; curricular need assessment, designing incentive packages, resource mobilization, involving stakeholders, post-literacy, averting functional illiteracy 
relapsing, and monitoring and evaluation). Though 5/13 IFAEP activities were planned, the author (during the interview and FGD sessions) was informed that the plans were not participatory and genuine. In connection with this, one of the interviewees (Exp 5) opined:

IFAEP plans are usually prepared for the "sake of planning" only. They, for one thing, are not participatory. I mean mainly done by top-level management. The other is that it (planning) seems nominal. Stakeholders' views are not exhaustively taken into considerations.

The above views were shared by 5 of the interviewees (Fac 1, 3; Cor 3 and Exp 1,3 ) and 3 of the FGD participants (Fac 4 and Exp 2, 4).

In principle, for the effective achievement of the goal, planning should engage all the staff, including concerned stakeholders working and collaborating in the same area (AE/FAE), and the same should be shared among them. So that synergy will be secured, which in turn helps in pooling resources of all kinds to realize the targeted goal. Nafukho et al. (2011) indicated that a plan is a map that directs us towards our end destination-to the achievement of our organization's vision. A good plan will also show us the things we need to do and the sequence of events that need to be followed.

During the FGDs, participants revealed their concerns about the clarity of the direction the current IFAEP is following. For instance, one of the FGD participants (Exp 4) stated:

...I think, the success of any organization depends on feasible planning, setting a clear direction, and working vigorously in a coordinated manner to successfully achieve the intended goal. Given this, however, our IFAEP lacks clear direction, I mean, where to start, how to go through, what and when to achieve is fuzzy. Since IFAEP is merged with the general education program, it lacks its own structure and thus, misses independent operation, which led to the absence of its own clear vision, mission, goal and values, which are keys to the fruition of the IFAEP program.

Consistent with these findings are research reports (local and overseas) made by authors such as Negassa (2019), Ito (2013) in Weldemichael (2018), Awgichew and Seyoum (2017), are few to mention. For instance, Negassa (2019) investigated that non-formal education such as IFAE is not well planned, structured and organized. In addition, Awgichew and Seyoum (2017) revealed their concern about the manner literacy programs are managed and suggested that the government should give due attention to planning, among other requisite works. Ito (2013) in Weldemichael (2018) reported that lack of coherent planning was one of the problems in AE programs.

To sum up, although pieces of literature (such as Ishaq and Ali, 2012) show a positive relationship between proper planning and effective implementation of FAE/AE, planning in the area of FAE is either lacking and/or inadequately addressed, which ultimately led to poor implementation and management of the 
IFAEP in the present study area. The major contributing factors, as the study revealed, were lack of the: clear vision and mission, qualified manpower in the area, structure, attention as well as misperception of the program and monetary constraints.

Implementation, which is the act of putting IFAEP into effect/practice as per the NAES/MoE's (2008) guideline, was the other variable studied in this paper. In this section, eight items related to facilitation skills of the facilitators, assessment of learners, treatment of adults with disabilities/special needs, delivery of lesson by year (level) and age (group), utilization of instructional media \& materials, and organization of practical learning programs were designed and then rated by the respondents. Accordingly, as indicated in Table 3, the results of the study are discussed hereunder.

Although the sub-variables (\#8) listed under Table 3 can be thought as some of the indicators and determinants of effective implementation of the IFAEP, the study unveiled that facilitators (volunteers, employed, formal school teachers, development agents, health extension workers, etc.) lacked andragogical skills required to facilitate adult learning, which is mainly attributed to the fact that the majority of them (90.8\%) were non-adult graduates (Section 3.1).

Consequently, facilitators were unable to deliver their responsibilities. For example, adult learners with special needs (adults with impairments like visual, hearing, and physical disabilities) in the adult learning centers, were not identified and special arrangements were not made to help them learn effectively. This is in contradiction with what is stated in the MoE's (2016) master plan for "Special Needs Education/Inclusive Education" in Ethiopia 2016-2025. The document boldly states that it $[\mathrm{MoE}]$ will provide quality, relevant and equitable inclusive education and training to all children, youth and adults with special needs education and ultimately enable them to fully participate in the socio-economic development of the country. The other is that facilitators were not able to use/demonstrate various instructional media and materials (audio-visual materials-AVMs) as well as practical sessions and visits to support adult learners. Subramony (2003) emphasized that the likelihood of learning and retention of what is learned increases when more AVMS are experienced by the learners-the more the senses organs are involved, the more the learning will be. Lack of organized and model centers such as Community Skill learning centers (CSLcs) and Farmers Training Centers (FTCs) were the major impediments for not to augment theoretical lessons with practical ones.

Although works of literatures (such as Davis, 2005) suggest that adults should learn in multiple modalities and approaches in a relaxed state and social environment involving multi-sensory and collaborative learning, the results of this study showed that this was not the case in the present study area. Similar findings were reported by scholars such as Seleshi (2019), Bidika (2016), and Seyoum and Amdemeskel (2016). Since facilitators are implementors of the IFAEP at the grassroots level, appropriate andragogical skills training should be given by the concerned bodies (such as MoE, district education bureaus, NGOs, etc) to ena- 
ble them to deliver their professional duties properly.

In addition, adults and youths, who significantly differ in their ages, life experiences and levels of understanding, were made to sit together and learn the same content in a class. Since their pace of learning, level of understanding as well as areas of interest to attend IFAEP vary, this can momentously affect their participation and mastering of literacy and livelihood skills. Evidences from observations, interviews and FGDs also affirmed that adults and youths were hoarded together. During the interview with one of the IFAE experts [Exp 3], he said: "Since adults are individuals who are 15 years and older, all individuals enrolled to attend IFAE classes, either she/he is 15 or 60 , are grouped in one class/batch". This finding is congruent with the research findings reported by Negassa (2019) in which he reported that young children, who are supposed to attend formal school, were attending FAE class with adults. To recap, current implementation of IFAEP, in general, is problematic, unable to deliver and needs due attention and timely corrective measures by the concerned bodies. Similar concerns were reported by Seleshi (2019).

Relevance (also referred to as curricular orientation in this paper) was another variable examined in this study. Curricula designed and delivered to adults are ought to be relevant to their daily life and improve their socio-economic, socio-political and socio-cultural status. In this regard, $\mathrm{MoE}$, in its various documents (such as MoE, 2017; 2016; 2015; 2011; 2008; 2006), in one way or another, revealed its strong belief that AE/FAE/IFAEP, upon its implementation, has the potential to lift the overall living conditions of the adults. In this regard, attempts were made in this study to assess the extent of relevance of IFAEP to the life of adult learners. Consequently, the study disclosed that current IFAEP's relevance to the lives of adults was moderate and above (Table 5) albeit few respondents revealed some degree of repudiations arguing that the program is well designed but its practical contribution in changing their lives was not appreciable. In connection with this, further explorations were made via interviews and FGDs.

Accordingly, in one of the FGDs held with EBHs, coordinators, and facilitators, all the participants, unanimously, articulated that all the adult training modules were thoroughly prepared-relevant, contextualized (culturally, linguistically, etc) and directed towards improving the all-rounded life of adults. Similar assertions were investigated by scholars such as Seleshi (2019), and Seyoum and Basha (2019). The participants, however, pointed out that the practice of realization of the program is too low and problematic due to various internal (to mean facilitator, expert, coordinator and learner-related) and external (government-related-attention and political commitment) problems. The latter expression appears to be in congruence with what MoE (2008) stated as: “...IFAE program had remained low in terms of accessibility and relevance; it had not been geared towards problem-solving and had failed to address the immediate life of the adult community".

Securing active, organized and sustainable participation of all the concerned 
bodies (such as local community, personnel, learners, facilitators, NGOs, NPOs (non-profit organizations, etc) is key to the sustained and successful functioning of IFAEP. These partners and stakeholders are potential sources of inputs (material, financial, and human) for the smooth running of the program. However, the present study found out that (Table 7) the engagement of the NGOs, NPOs, local community and facilitators, unlike adult learners, is low and in some cases non-existent. Governments, especially poor countries such as Ethiopia, can't cover all the costs needed to run IFAEP. Thus, this calls for the poor countries (such as Ethiopia) to partner and work with GOs, NGOs and others. The only NPO operating in the present study area (though not broad in its coverage), is the Harar Catholic Secretariat (HCS). In connection with this, one of the interviewed EBHs [EBH1] asserted:

By its very nature, IFAEP implementation calls for the co-action and synergy of different parties. Our education bureau, with its limited resources (human, material and financial), can't fully realize the implementation of the IFAEP. It needs concerted efforts and commitment of all the concerned bodies such as GOs, NGOs and religious organizations including our local community (parents, businessmen, facilitators/teachers, adult learners, etc.) so that IFAEP will be run as per the guidelines outlined in the NAES document. In view of this, the current status of involvement of the stakeholders in IFAEP implementation, in our zone, is very low.

The above reflection was shared by the majority of interviewees and FGD participants. Consistent with these findings are research reports made by such as Negassa (2019), Awgichew and Seyoum (2017), and Negash (2006). They asserted that participation and contributions of the NGOs, as well as GOs and private sectors in the implementation of the IFAEP is low. Aids and supports from NGOs and GOs (including MoE), when available, are usually low for IFAEP and mainly tied for political consumption; used for formal education and few for democratization process but not to cover the expenses of adult/non-formal education. Kenea (2014) concludes that whatever the rationale for a literacy program is, the curriculum (why, what and how it is provided) is more often influenced by the objectives (or intents) of the providers than by the demands of the learners themselves. This conclusion is also in line with the findings made by Workineh (2012) in which he stated that ... providers do their Own things giving minimum focus to the beneficiaries.

Like participation of the stakeholders, sectoral integration (partnership and collaboration among key ministerial offices), plays a paramount role in the proper functioning of the IFAEP. MoE (2008), in its NAES document, stated: “.. . it is necessary to provide the sector [IFAEP] with coordinated management through coordination of relevant ministries for agricultural and rural development, health, women's affairs, youth and sports, labor and social affairs, and thereby organizing adult education in a strengthened and coordinated manner based on the decentralized administration system of the country." 
Integration is the backbone of the IFAEP. However, it seems that the entire burden is left to the ministry of education/education sector at different levels. The policy document in AE presupposes the "real" integration and cooperation among the different sectors so that they will together plan, share vision, responsibilities and pool all the required resources (human, material and financial), execute and monitor and evaluate the successes and failure of the IFAEP. However, miserably, as the findings of the present study as well as a review of local studies (Gudeta, 2017; Girmay, 2017; Haile, 2014; Negassa, 2019) unveil, integration was almost non-existent and/or very low. The expected levels of integration (conceptual linkages, policy and strategy, institutional/sectoral, programmatic design and implementation and impact for target group) (ADEA, 2012) are missing. This has accounted for the crisis and poor implementation of the IFAEP in the study area. This alarms the sectors to re-establish their integration and gear IFAEP to the desired goal to make it contribute to the national and individual [adult learner] development.

Monitoring and evaluation (M\&E) was the other variable studied in this paper. It is a powerful tool to measure and know how much of our planned activities are accomplished, and how. It is one of the vital elements of the effective management of the IFAEP and helps us know our level of success. However, as shown in Table 8, from a total of 6 items designed and presented to the respondents, except two of them (learner follow-up and evaluation of the overall operation of IFAEP through formal reporting), all the rest were either not planned or not carried out [not monitored and evaluated] by the education bureaus and other concerned bodies.

Further explorations were made to validate the above views. Accordingly, the researcher's observations and examinations of the documents related to IFAEP learners such as their academic records (for instance, assessment results), follow-up checklists, attendances, dropouts, class repeaters, etc were poor and in some centers non-existent. Furthermore, it was noticed that planning for enrollment was not based on actual headcount conducted at the district level, but the number of the adult population had been taken from the national population census (conducted every 10 years) of the country. This means planning was not based on contemporary statistics. On the other hand, the researcher observed a good record of enrollment statistics organized by year, gender, location (district, Kebele, centers, etc.) and status of the learners as active learners and graduates. Hoy and Miskel (1978: 215), in Negassa (2019), stated: "policies are not only formulated but also communicated, monitored and evaluated". Awgichew and Seyoum (2017) reported that monitoring and evaluation tools and techniques were not employed in the IFALP. One of the interviewees [Cor 3] asserted:

The current FAL program lacks due attention. Periodic supervisions are not carried out and feedbacks are not given. To me, it is a nominal program for adults. We are simply expected to make reports, even from the scratch and 
communicate the same to the concerned offices. Our reports are sometimes specious assuming that everything is fine. Overall performance evaluations are usually made only through these reports.

Several challenges have constrained the effective implementation of the current IFAEP. According to the findings of this study (Table 9), the major challenges that negatively affected the effective implementation of the IFAEP in the present study area in particular and in Ethiopia, in general, are lack of clear vision, mission, goal and values; organizational structure, proper understanding, adequate resources (trained manpower, budget, and required materials), interest, motivation and commitment by staff, incentives, sectoral integration and guidelines.

With regard to the challenges constraining IFAEP implementation, interviews and FGDs were held with the participants of this study. Accordingly, in the FGDs held with facilitators, EBHs, coordinators, and experts, the majority of them believed that IFAEP in their Zones was in acute problems and entangled with countless challenges. Of which, the major ones, as they listed, were lack of resources (human, financial and material); meager incentives; lack of awareness, motivation and interest among staff; lack of clear direction (vision, mission and goals) and harmony among concerned offices (which was presumed to be the backbone of the IFAEP).

The discussants also stressed that the budget earmarked for a district to run all its IFAEP related issues (incentives, purchase of items, trainings, etc) was only 25,000 Ethiopian Birr [ETB] (which is equivalent to about $\$ 850$ at current exchange rate). They indicated that due to the lack of attention and shortage of budget, it seems that the program is paralyzed- "stuck in between death and life". As a manifestation of this situation, they mentioned that adult learners attend their lessons under tree shades, thatches, private houses, forlorn houses and open areas. In addition to these, staff, particularly facilitators are paid low (about $1013 \mathrm{ETB} \sim \$ 30$ per month for regular facilitators and $12 \mathrm{ETB} \sim \$ .34$ per period ( 2 hours) for part-timer facilitators). As a result of these, facilitators are not motivated and committed to their job. Turnover is high among facilitators; competent facilitators were not attracted to the program. Thus, anybody who shows interest to be a facilitator can teach adults in the study area. It was also indicated that coordinators, experts and facilitators were not graduates of adult education programs (Section 3.1) and lacked the art of management and facilitation of adult education.

Myriads of empirical studies have been conducted in this area. Thus, the best part of the above findings is consistent with the research findings reported by Shenkut (2005); Workineh (2012); Gelana (2014); Seyoum and Basha (2017); Seleshi (2019), Awgichew and Seyoum (2017); Ukwuaba (2015); Negassa (2019); and the like. These authors indicated that the current IFAEP is disadvantaged by several factors. I have categorized these factors under the themes as resource-related problems/challenges; institutional (structural) problems, aware- 
ness problem; and government-related problems. The major resource-related problems are lack of trained professionals in the area of IFAEP who can competently facilitate adult learning, and/or execute managerial activities/functions (such as planning, organizing, staffing, directing and controlling) as effective management is needed to ensure the coordination of individual efforts, guide human and physical resources to attain institutional objectives. The other resource-related problem is the shortage of required materials/facilities in a needed quantity. The institutional problem refers to the structure (position) of the IFAEP) in the education system/structure of the country. Findings indicated that IFAEP lacks its own academic and administrative structure. It is not an independent organization (now placed as a unit under education bureaus). This has created problems related to Ownership, budget allocation and accountability. As to the awareness-related problems, results of the present study as well as literatures indicated that stakeholders broadly misconceived the program-lacked a clear understanding of the what and why of IFAEP. Government-related problems refers to the political willingness and commitment to Own the program and allocate adequate resources required to the run IFAEP, and thus make maximum benefits out of it for the advantage of adult learners in particular and the country in general. Overall, one challenge compounded with the other has made the program unattractive and less effective.

\section{Conclusion}

The quantity and quality of inputs (human, material and financial resources) we invest in education determine the quality of the output. With the same token, training of adults, through IFAEP, who are knowledgeable, skilled, capable of identifying and tackling problems, and contributing to the poverty reduction endeavour of Ethiopia requires the provision of quality adult education in a well-coordinated manner. However, the present study revealed that IFAEP is not well-managed in terms of planning, participation of the stakeholders, implementation, integration, and monitoring and evaluation. The program is run by unprofessional personnel. It has suffered from lack of resources (trained manpower, finance and infrastructure) which severely shackled and bottlenecked it. The implication is that adult learners couldn't make benefit from the program.

Ineffective management of IFAEP contributed to the inadequate implementation of IFAEP, which in turn leads to the inability of the government to achieve its NAES objectives. The study also showed the major policy-practice gaps in the program. Thus, this study will be important theoretically, practically and policy-wise. Theoretically, it contributes to the existing body of knowledge and literature in AE/IFAEP; and practically, it helps practitioners and managers of AE/IFAEP to deal with the existing problems in its implementation, and it will also serve as an input for policy-makers and experts to revisit the way current IFAEP policies and strategies are designed and implemented. This study also gives insight into mechanisms of improving the present status of IFAEP. 
To improve the present status of IFAEP management and make it worthwhile in improving the lives of adult learners (such as in terms of earning livelihoods, self-sufficiency, educating their children, using modern technologies, leading healthy life styles, etc.) and contribute to the national agenda of poverty reduction, the following recommendations should be taken into consideration. First, the MoE and its partner sectoral ministries, should integrate and perform their part as per the duties and responsibilities depicted in the NAES/MoE's (2008) IFAEP implementation guideline. The same group should closely work and influence concerned government bodies for Adult and Non-Formal Education (ANFE, inclusive of IFAEP) to have its own broad administrative and academic structure (which leads to the establishment of an independently operating unit) so that many critical problems, such as, related to the sense of ownership, accountability, and resources (financial, material, and human) those seem to be clung on structure of ANFE will be resolved. This obviously calls for the political will and commitment of the officials among the ministerial offices (sectorally integrated) and other concerned government bodies to rigorously work on. Second, education bureaus at regional, zonal and district levels should give due attention to the program in terms of planning (feasible), implementation, integration and cooperation and collaboration between and among stakeholders (like local community, private sectors, partners, religious institutions, etc.), resource mobilization and allocation, and monitoring and evaluation. This program seems to be forlorn. Thus, the $\mathrm{MoE}$ (as a leading ministry for IFAEP) along with the education bureaus, should make the sector [IFAEP] attractive in terms of salary, incentives, motivation and resources.

Overall, for the sustained operation of the IFAEP, adequate human, material and financial resources should be pooled through effective integration, partnership and stakeholders' active participation such as GOs, NGOs, religious institutions, private sectors, local community, etc.). Lastly, it is suggested that further studies be conducted to have a full understanding of the IFAEP in different Zones of the same region in particular and in Ethiopia in general.

\section{Funding}

Self-sponsored.

\section{Conflicts of Interest}

The author declares that there is no potential conflict of interest in this paper.

\section{References}

ADEA (2012). Integrating Basic Education, Life and Vocational Skills within a System Approach for Adult and Non-Formal Education: Experiences, Lessons Learnt and Outlook from an Ethiopian Perspective. Tunis Belvédère: Association for the Development of Education in Africa (ADEA).

Awgichew, S., \& Seyoum, Y. (2017). Integrated Functional Adult Literacy: Existing Practices and Challenges in Eastern Ethiopia. International Journal of Education and Lite- 
racy Studies, 5, 86-97. https://doi.org/10.7575/aiac.ijels.v.5n.4p.86

Bartlett, E., Kotrlik, W., \& Higgins, C. (2001). Organizational Research: Determining Appropriate Sample Size in Survey Research. Information Technology, Learning, \& Performance Journal, 19, 43-50.

Bidika, K. (2016). An Investigation on the Practice of Integrated Functional Adult Literacy in Benishangul Gumuz Region. Global Journal of Human-Social Science: Linguistics \& Education, 16, 1-19.

Creswell, J. W. (2008). Research Design: Qualitative, Quantitative, and Mixed Methods Approaches. Thousand Oaks, CA: Sage Publications

Creswell, J. W. (2012). Educational Research: Planning, Conducting, and Evaluating Quantitative and Qualitative Research (4th ed.). London: Pearson Education, Inc.

Creswell, J., \& Plano, V. (2007). Designing and Conducting Mixed Methods Research. London: Sage Publications.

Davis, N. (2005). Just in Time Support for Educational Leadership. In Education and the Knowledge Society: Information Technology Supporting Human Development (Vol. 161, pp. 271-277). Berlin: Springer. https://doi.org/10.1007/0-387-23120-X_29

Drost, E. A. (2011). Validity and Reliability in Social Science Research. Education Research and Perspectives, 38, 106-114.

Ethiopia National Human Development Report (2018). Industrialization with a Human Face.

http://hdr.undp.org/sites/default/files/ethiopia_national_human_developme-nt_report 2018.pdf

Gay, L., Mills, G., \& Airasian, P. (2006). Educational Research: Competencies for Analysis and Applications (8th ed.). Upper Saddle River, NJ: Pearson Education, Inc.

Gebremedhin, T. G., \& Tweeten, L. G. (1994). Research Methods and Communication in the Social Sciences (p. 55). Westport, CT: Praeger Publishers.

Gelana, G. (2014). An Assessment of Ethiopia’s Progress towards Attaining Integrated Functional Adult Literacy. Bahir Dar Journal of Education, 14, 14-28.

Girmay, S. (2017). Practices and Challenges of Integrated Functional Adult Education in Arada Sub-City of Addis Ababa. MA Thesis, Addis Ababa: Addis Ababa University.

Gudeta, A. (2017). A Study on Integrated Functional Adult Education Program in Pastoral Communities of Jarar Zone, Somali Regional State: Challenges and Opportunities. International Journal of Innovation Research and Development, 6, 90-98. https://doi.org/10.24940/ijird/2017/v6/i7/MAY17077

Haile, H. (2014). Practices and Challenges of Integrated Functional Adult Literacy Programme: The Case of Kolfe Keranyo Sub City. MA Thesis, Addis Ababa: Addis Ababa University.

Ishaq, A., \& Ali, M. (2012). Effective Planning as a Potent Tool for Implementing Adult Literacy Programmes: Implications for Achieving the Millennium Development Goals in Gombe State, Nigeria. Journal of Economics and Sustainable Development, 6, 93-99.

Kenea, A. (2014). Adult Basic Literacy "Initiatives" in Ethiopia: Change and Continuity. Journal of Critical Education Policy Studies, 5, 338-361.

Kowalski, T. J. (1998). The Organization and Planning of Adult Education. Educational Leadership Faculty Publication, Paper 61. University of Dayton. http://ecommons.udayton.edu/eda_fac_pub/61

MoE (Ministry of Education) (2006). Technical and Vocational Education and Training Sector. Non-Formal Technical and Vocational Education and Training Implementa- 
tion Framework. Addis Ababa: Ethiopia.

MoE (Ministry of Education) (2008). National Adult Education Strategy, February 2008. Addis Ababa: Ethiopia.

MoE (Ministry of Education) (2010). Learning for Life: Master Plan for Adult Education in Ethiopia 2010/11-2019/20. Addis Ababa: Ethiopia.

MoE (Ministry of Education) (2011). Functional Adult Literacy Implementation Guideline. Addis Ababa: Ethiopia.

MoE (Ministry of Education) (2015). Education Sector Development Programme $V$ (ESDP V) 2015/16-2019/20 G.C. Programme Action Plan. Addis Ababa: Ethiopia.

MoE (Ministry of Education) (2016). A Master Plan for Special Needs Education/Inclusive Education in Ethiopia 2016-2025. Addis Ababa: Ethiopia.

MoE (Ministry of Education) (2017). Education Sector Development Program IV, FDRE. Addis Ababa: Ethiopia.

Nafukho, F., Wawire, N., \& Lam, P. (2011). Management of Adult Education Organizations in Africa. Hamburg: UNESCO Institute for Education.

Negash, T. (2006). Education in Ethiopia: From Crisis to the Brink of Collapse. Discussion Paper 63. Uppsala 2006, ElandersGotab AB.

Negassa, T. (2019). Challenges of the Implementation of Integrated Functional Adult Education (IFAE) in Ethiopia: A Case of Oromiya National Regional State. African Educational Research Journal, 7, 103-117. https://doi.org/10.30918/AERJ.73.19.022

Papen, U. (2005). Adult Literacy as Social Practice-More Than Skills. London: Rutledge. https://doi.org/10.4324/9780203347119

Sandhaas, B. (2009). Portrait Adult Education Ethiopia. Addis Ababa: DVV International.

Scott, D., \& Morrison, M. (2006). Key Ideas in Educational Research. London: Continuum International Publishing Group.

Seleshi, B. (2019). Implementation of Adult Education Program in Hawassa City Administration: Practice and Challenges. IOSR Journal of Humanities and Social Science, 24, 48-51.

Seyoum, Y., \& Amdemeskel, Y. (2016). Determinants of Adult Education Program: A Critical Analysis of Adult Education in Some Selected Training Centres of Eastern Regions. Humaniora, 7, 545-554. https://doi.org/10.21512/humaniora.v7i4.3607

Seyoum, Y., \& Basha, G. (2017). Andragogical Methods to Sustain Quality Adult Education in Ethiopia. International Journal of Instruction, 10, 47-62.

https://doi.org/10.12973/iji.2017.1034a

Seyoum, Y., \& Basha, G. (2019). Status and Relevance of Adult Education: Learners Perceived Experience in Eastern Ethiopia. In J. K. Mugo, Namubiru-Ssentamu, \& K. Njihia (Eds.), The Good Education and Africa's Future: Concepts, Issues and Options (pp. 170-205). City: Paulines Publications Africa.

Shenkut, M. (2005). Ethiopia: Where and Who Are the World's Illiterates? 2006/ED/ EFA/MRT/PI/57, UNESCO.

Singh, K. (2007). Quantitative Social Research Methods (p. 108). Thousand Oaks, CA: Sage Publications Inc. https://doi.org/10.4135/9789351507741

Sonja, B. (2011). Literacy Skills Training and Entrepreneurship-Support for Rural Women in Ethiopia. In M. Samlowski (Ed.), Adult Education and Development (No. 77). Bone: DVV International.

Subramony, D. P. (2003). Dale's Cone Revisited: Critically Examining the Misapplication of a Nebulous Theory to Guide Practice. Educational Technology, 43, 25-30. 
http://www.jstor.com/stable/44428845

Ukwuaba, L. (2015). Constraints on the Implementation of Adult Education Programmes in Nigeria. International Journal of Education and Research, 3, 247-254.

UNDP (2009). Handbook on Planning, Monitoring and Evaluating for Development Results. New York: UNDP.

UNESCO (2019). Data for Sustainable Development Goals (SDGs). UNESCO Institute for Statistics. http://uis.unesco.org/en/country/et

Weldemichael, F. (2018). Integrated Functional Adult Literacy Education for Empowerment and Sustainable Development in Ethiopia: A Comparative Study of Tigray and Amhara Regions. Oslo: The University of Oslo.

Workineh, T. (2012). The Adult Education Practice in Ethiopia (2nd ed.). Addis Ababa: Alpha Printers.

World Population Review (2020). Poorest Countries in the World 2020. 